\title{
Facilitating digital transformation through education: A case study in the public administration
}

\author{
Birgit Schenk \\ University of Public Administration in Ludwigsburg \\ birgit.schenk@hs-ludwigsburg.de
}

\author{
Mateusz Dolata \\ University of Zurich \\ dolata@,ifi.uzh.ch
}

\begin{abstract}
The need for qualified people to manage the digital transformation in public administration is tremendous. University curricula require adjustments to qualify graduates adequately. Business and engineering departments run practice-oriented university courses to tackle real-world digitalization challenges. In doing so, they shaped digital transformation in many companies. While potentially effective, such approaches remain rare in public administration teaching. It is unclear how to combine a contemporary, practice-oriented training approach towards digitalization with the contents of public administration curricula. The paper outlines the structure and methods employed in a course offered to public administration students at a German University. The preliminary evidence shows that the course was successful among students and practice-partners. Overall, the paper illustrates how public administration universities can contribute towards digital transformation by collaborating with municipalities and by empowering students to manage and drive digital transformation in the public sector.
\end{abstract}

\section{Introduction}

Digital transformation disrupts businesses and the economy. This change also affects government and public administration [1]. The administration is expected to catch up and boost the advantages of modern technologies on the one hand, while acting ethically and in favor of the citizen on the other. Given this challenge, public administration requires impulses to drive digitalization and to encourage capable employees to deal with it. However, current public administration employees and students are just prepared for routine tasks and see IT as an instrument "to reinforce existing organizational arrangements and power distributions, and that this trend will continue into the foreseeable future" [2, p.7]. Instead of embracing IT as a chance and a mechanism to disrupt processes, work practices or communication with citizens, public administration preserves the past with modern tools [3]. Since municipalities and government agencies lack competencies to exploit the value of digital transformation [4], they fall below the private sector standards. This manuscript presents a way to tackle this issue: a practice-oriented digital transformation course involving fieldwork and user engagement designed to fit the context of public administration.

Public administration schools have the potential to impact the digital transformation in the public sector. On the one hand, by tightening collaboration and establishing common practice projects with municipalities and government agencies, the universities can accelerate the transfer of knowledge to the public administration and its employees. On the other hand, by encouraging the students to engage in real-world digitalization issues, universities can provide the qualified workforce for any future challenge. This article discusses how public administration schools can contribute to this development.

To boost their potential, the schools need new approaches towards teaching and research. In particular, students should be given the opportunity to tackle realworld problems on their own. At the same time, public sector needs research collaboration that accommodates innovative digital intervention. Yet, the primary mission of schools and universities is teaching and training in such a way that digital transformation could be intervowen within the curriculum and give the students the chance to formally improve their qualifications. Public administration schools have to establish new training and research methods in order to make their impact on digital transformation in the public sector effective, sustainable and consistent with their primary tasks.

Inspired by the developments in the business and engineering departments, we envisage a university course that brings together students and public sector employees to solve an urgent public agency issue. Conceptualizing and running such a course involves multiple challenges: from finding agencies willing to participate, to choosing the right methodological approaches, right up to balancing the workload for students and teachers. This article will touch upon those points. However, the most problematic aspect is to find an agreement between the contents described in the core curriculum and the flexibility necessary for creative work in a real-world context. Hence, the main objective behind the case study presented here was to identify a way to combine a contemporary, practice-oriented teaching approach to- 
wards digitalization with the contents of public administration curriculum. The proposed design has undergone a twofold evaluation: the feasibility of the course was tested at the University of Public Administration and Finances of Baden-Württemberg in Ludwigsburg. The effectiveness of the course design was tested, at the end of the course, by collecting the opinions of students and project partners. Overall, we conclude that publicadministration education requires practice-oriented, hands-on courses. We show that such courses are possible, but require additional effort to organize, facilitate, and run the course. We also provide evidence of the impact of such courses on the communes and students.

The results are relevant for a wide audience. First, faculty at public administration schools can benefit from an exact description of the course and replicate it in their institutions. Second, managers in the public sector can find evidence for the value of collaboration between public sector and education institutions. Third, decision makers who drive digital transformation in the public sector can find inspiration on how to set new impulses beyond the typical top-down or bottom-up approaches. Overall, this paper suggests that education might be the way to tackle the sluggish digitalization processes in public administration.

\section{Digital Transformation - generator of new requirements and skills}

Digital transformation is the novel use of digital technology to solve practical problems [6]. It makes possible new types of innovative and creative solutions, rather than simply extending and supporting conventional approaches. "The ultimate stage is that of digital transformation and is achieved when the digital usages which have been developed enable innovation and creativity and stimulate significant change within the professional or knowledge domain" [6 p.173]. Accordingly, the essence of digital transformation is not the digitalization or digitization of known processes but providing technology-based solutions to old and new challenges. There are numerous challenges in public administration: higher expectations from citizens, dependency on political agendas, and complex developments in municipalities (especially in booming cities), just to mention a few. Those challenges require new solutions to which modern technologies offer potential answers but public sector often lacks human and financial resources for exploration, choice, and implementation.

Nevertheless, public administration tried to exploit the benefits of digitalization, though results are not satisfactory [7]. The last big wave of digitalization resulted in development and launch of websites for single agencies, municipalities or even departments, where the citizen could find key information, download brochures as
PDFs, or carry out basic transactions. But digital transformation could be more than that $[8,9]$. Private business increasingly invest in holistic solutions with seamless media usage to ensure efficiency, sustainable structures and processes for service delivery [10, 11]. But to offer high-quality services, public administration needs to (a) design its e-services to an up-to-date level in technology and content, (b) adjust or reorganize its business processes or organizational structures, and (c) take the citizen's perspective. We claim, that they have much to catch up to fulfill their role of facilitating digital transformation. The public sector requires adequate management practices to regulate the transformation, welltrained staff to drive the change and structures to create problem-oriented interdisciplinary teams. Overall, the public sector in many developed countries still lacks a consistent and citizen-friendly strategy for digital transformation and relies on singular improvements.

Implementing a proper digital-transformation strategy requires the right people and skills. Kirchner et al. [12] identify 18 competences expected to play a primary role in the upcoming digital transformation processes: (a) Key non-digital competences: entrepreneurial thinking and self-initiatives, adaptability, creativity, problem-solving perseverance. (b) Key digital skills \& competences: digital literacy, digital interaction, collaboration, data literacy, digital learning, digital ethics, agile working. (c) Technological competences: technological skills, tech-translation (to moderate between non-technical experts and technical experts), user-centered design, web-design, complex data analysis, conception \& administration of networked IT systems, smart hardware/robotics design \& development, and blockchain technology. It is clear, that the technological competences can be integrated via consulting companies or private-public partnerships. But for such collaboration to work, the public sector requires key digital and nondigital competences to accommodate the technological improvements at all organizational levels. However, those competences and skills are still missing in the curricula of public administration schools and, hence, also in the public agencies and municipalities [11].

\section{Digital Transformation in Public Ad- ministration Curriculum}

This manuscript proposes a new approach for transferring of skills and competences to public sectors and takes on practices from business and engineering schools. They have been offering award-winning courses, which confront the students with practical challenges provided by the industry and let them collaborate directly with the industry partners to solve the challenges $[13,14]$. Those courses are structured according to the general design paradigm (problem identification, solution design, and evaluation) and rely on processes 
and tools from design thinking $[15,16]$ and similar approaches. Whereas some leading universities made the initial step decades ago $[16,17]$, other schools followed, so that modern engineering and business education relies on challenge-driven project work. As a consequence, companies benefit from the students' fresh view, methodological mentoring from teachers, and can extend their competences; in the long-term, the workforce market benefits from graduates, who are prepared for solving practical challenges and possess the right skills. In the short term, students get access to interesting practical problems, understanding of the context where they can apply their theoretical knowledge, and an opportunity to make real-world impact. Finally, universities improve their curricula and gain access to research fields. Inspired by these approaches and their positive resonance in industry and schools, we launched a course that adopts the core ideas from engineering and business schools for use in public administration education.

Previous research acknowledges digitalization is a challenge as well as an opportunity for higher education [18]. Universities benefit from higher demand for skilled and well-educated professionals, but still struggle with providing an adequate teaching offering [19]. There have been frequent calls for including digital transformation in public-administration curricula [20, $21,22]$, but only few articles offer practical guidance $[23,24,25]$. Hence, no best practices have been established so far [26]. Public-administration teachers intending to address digital transformation in their courses, need to start from scratch: they need to know various methods and topics, assess their didactic value, establish a coherent plan and, finally, introduce the course. Depending on the particular environment and the teacher's background, this might take years of hard work.

It is important to note, that we do not address educating about digital transformation but discuss how to teach digital transformation. This aligns with e-government education research, which puts focus on acquiring practical and managerial skills rather than on abstract knowledge [26,9]. However, our merit differs from egovernment education research in one central aspect. Whereas e-government education focuses on leaderlevel curricula, i.e., on educating future chief information officers and decision makers for public administration [26], this paper addresses the education of future public servants and employees, whose role in driving digital transformation was previously underestimated. While agreeing that digital transformation needs well-prepared leaders, the transformation can only succeed if other employees bring the right competencies.

\section{Background: Status quo and key needs}

The University of Public Administration and Finance of Ludwigsburg (HVF) offers "Public Administration B.A." [27], a study program on public administration with subject-related topics such as Administrative Procedural Law, Administration Theory, Public Finances, etc. Basic lectures are offered in the first three terms. Then students work in various departments in public administration over 14 months (three terms). The program covers theory (terms one to three) and general skills (terms four to six) but ignores the necessity to prepare students for digital transformation - at least, not during the first six terms. In particular, no courses address the practical aspects of work with existing IT systems, forcing communes to additionally qualify the employees. Even worse, no courses consider digital transformation as an ongoing process which radically changes the daily practice of public administration and reflects the need to prepare the students for work in this highly flexible environment. Only students who choose the specialization area "Human Resource, Organizational and Information Management" in their final, seventh term, have the chance to attend a single module of 4 hours per week dealing with digital transformation. The students in this area are on average 20-22 years old, being digital natives, have completed A-levels prior to joining the school and attended the courses described above. $65 \%$ of the students are women. The graduates are likely to work in public sector's organizational and human resource departments or, if such exist, in digitalchange departments.

Digital transformation is a real-world problem and managing real-world problems needs both: theoretical and practical competencies. Future public employees have to deal with competing and conflicting demands from clients and the general public, with ongoing technological change, and new legal circumstances. Despite those challenges, the model of public employees' education resembles the 1990's: "chalk and talk", groups of up to 35 students, or single-discipline lectures. Developments in student-centered learning, such as projectbased learning, have so far had made little impact on the mainstream public administration education. Thus, students graduate with a good knowledge of fundamental law and public finance but unprepared for digital change. For instance, they lack capabilities to transfer theoretical knowledge to practice [28]. Overall, the focus and methods applied at the HVF are representative for the public administration curricula - public administration studies hardly ever deal with digitalization and they focus more on content than competence [29].

To supersede the present teaching model and to train the competencies needed, methods and content of courses need to change. Methodical changes prepare the students for dealing with the practical reality of digital transformation. Since digital transformation comes with projects [21], project-based learning appears adequate. 
It is based on self-direction, self-initiative as well as collaboration, and is multi-disciplinary. The chosen project

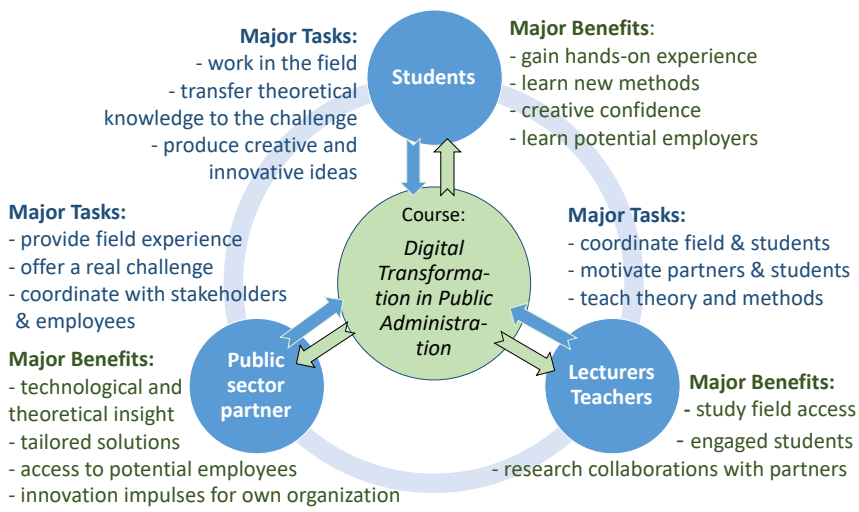

Figure 1. Tasks and benefits within the course.

challenges are close to professional reality and are developed prior to the course, by teachers together with representatives from the public sector. Projects require application of previously acquired knowledge and are accompanied by subject courses. The students have to manage time and resources as well as their task and role differentiation. They need to consider typical development risks, i.e. while employing agile project management. They work in teams with teachers as advisers [30, 31 and collaborate with public administration practitioners and citizens [32]. This gives the students the opportunity to learn the daily work of public administration, to collect background knowledge and identify key drivers and obstacles for digital transformation. The municipalities and practitioners involved see great benefit from the work and solutions gained by students. Figure 1 illustrates the interplay between students, teachers, and practitioners. Overall, in terms of method, the proposed course recognizes that public administration studies provide too little opportunity to strengthen problemsolving and group-work competencies and implements project-based approach from engineering or business education $[13,14,15]$.

Through content adjustments, the students should extend their digital literacy and learn about processes involved in digital transformation, such that they can effectively engage in translation of identified problems and solutions into technological concepts. The students of public administration are not technology specialists, the competences which must be met by the new course are basically (a) digital and (b) non-digital key competences [12]. Digital competences are digital literacy, digital interaction, collaboration, data literacy, digital learning, agile working. Non-digital competences are self-initiative, adaptability, creativity, problem solving, perseverance and project management. To identify the course contents, we worked through different concepts of digital transformation [33] and digital maturity [34,
35]. Considering these and the given workload we focused on four aspects: new technologies and trends, visioning and service (re)design, business process (re)design and organizational structure. Additionally, students need to consider aspects typical for the public sector. For instance, in Germany the federal structure might facilitate or hinder digitalization in specific areas. Students need to learn to take those federal structures into account and focus on scalable solutions to meet business process requirements from towns to administrative regions. They also need to be aware of service trends outside public sector (omni-channel services, self-services, seamless customer experience, etc.) to accommodate future expectations of citizens/clients. The overall choice of content leads to a strategic vision as well as anticipating and shaping the public sector for the future.

\section{Course Programme}

Taking the methodological and content-related deliberation into account, we identified five units to structure the course: (0) basic knowledge and experience, (1) needs-driven analysis of the "real" world, (2) future trends and developments, (3) point of contact and service design, (4) organizational (re)structuring and process(re)design. Each unit covers specific content and includes training concerning adequate methods. The course structure can easily be adapted to various areas of public administration. At the HVF, we employed a structure to address real-world challenges coming from various departments of municipal administrations. Here, we explain the structure of the course while referring to the actual example of 2018's course: "Building Authority". The students were given the challenge to improve the citizen's experience how to obtain a building permit. Obtaining a building permit is a complex issue and involves multiple contact with the authorities (apart from the building authority, contact with the environment protection agency or the fire protection department might be necessary) as well as with external stakeholders i.e. architects or neighbors. A building permit is also necessary not only for citizens intending to build a new house, but also for those who make alterations to their property i.e. putting in a dormer window or constructing a carport. The municipalities involved saw the case for building permit as an interesting challenge because of mixed opinions from the citizens concerning the status quo. Here, we describe how students were instructed to work on that issue throughout the course. We refer to particular methods and techniques students are advised to use in each unit as well as to the rationale behind those methods and the content covered in the respective units.

\section{Unit 0: Basic knowledge / experience}

To be able to manage such a complex project, general knowledge and competences are required. During 
basic studies in the first three terms students had attended lectures teaching this. Therefore, in unit 0 they are asked to work through their former learning material and if they need additional help, to approach teachers for help. Additional material is offered concerning the challenge (building permit) to extend the basics.

Method: Literature studies based on self-learning. From the very beginning students are asked to work in teams and use a learning and a collaboration platform in order to exchange sources and knowledge.

Content: Students prepare for project work by learning about project management and agility, business process management, change management, empirical methods and techniques (e.g., survey construction).

In Unit 0 , the students acquire skills related to selfstudy and problem-space exploration. They gain experience in team building and initial organization and collaboration of teamwork, digital learning and interaction, self-initiative perseverance and agile working. This list shows that the competences addressed in Unit 0 are underlying all units.

\section{Unit 1: Needs-driven analysis of the real world}

In Unit 1, students need to identify, collect, document and analyze issues, which are characteristic for their challenge. This may include information needs and requirements, status-quo business processes, existing ways of information provision and current service strategy. Thereby, students take on the perspective of the stakeholders involved, mainly, citizens and employees.

Method: First, students complete mystery shopping (actual visits to building authority), mystery calls (actual phone calls to building authority) and online self-service (walkthrough through online resources) based on a given case, e.g., "I want to build a dormer". Then they identify problems / barriers, supportive / hindering aspects based on their own experiences in their case. Secondly, students carry out participating observations as well as interviews with employees and managers working in the building authorities in different municipal administrations. They have to identify problems / barriers, as well as supportive / hindering aspects employees have to face in serving their customers. This helps the students to establish empathy and to understand views of citizens and employees - not only in their explicit demands and requests, but also their emotions. The students learn how to cope with these, not only in terms of changing existing IT problems or inefficient IT-supported processes, but also in terms of a broader spectrum of issues, including non-specific work description, interpersonal problems or missing competencies, as well as uncertainty affecting daily work in public agencies.

Content: By working with citizens and employees, students learn the processes involved in obtaining a building permit. Apart from that, they learn, in supervised sessions with the teacher, about business process elicitation, as well as key aspects of organization of and structure in public administration. They also learn about different aspects of service delivery, consider blueprints for service quality and learn how to apply these into practice. Finally, they learn about the service provision as a collaborative undertaking involving the citizen and the public service employee, as well as the whole backoffice machinery behind the service. Consequently, students experience the importance of organizational context as an aspect of digital transformation. At the end of Unit 1, the students formulate a clear problem statement to be addressed in the subsequent units.

Unit 1 demands that students collect skills and knowledge necessary to identify and specify the actual problem behind a general challenge. In doing so, they traverse the first stage of the design paradigm. They master methods and techniques of empirical work such as needs driven approach, interviewing, participative observation, mystery calling / shopping. Furthermore, this unit offers them access to the relevant content that helps them frame their observations in practical and conceptual terms. Accordingly, they acquire knowledge and skills necessary to analyze the status quo and to explore the pain points together with the stakeholders. This prepares them for dealing with contradictory voices and organizational obstacles concerning the digital transformation. Simultaneously, the authorities benefit from student's work by receiving systematic and independent feedback concerning their strengths and weaknesses.

\section{Unit 2: Trends and Developments}

In Unit 2, students need to identify new paradigms (and not only technologies!) with potential to solve the challenge and to greatly improve public administration. Following the principle of Rob Nail [36], who said „one of the things that we try to help organizations do first is to have a perspective around technology and exponential technologies and then build in processes to constantly track and be aware of the trends, the potential opportunities and threats that are arising", students have to envisage a stakeholder-centered „perfect” public administration. Unit 2 implements the idea of dark horse prototyping [37] so that the students are encouraged to question both implicit and explicit assumptions and radically rethink public administration. For instance, today's law barriers (which demand, e.g., handwritten signature) can and should be ignored. Working on their vision, students are asked to think the unthinkable and to make the seemingly impossible possible, while considering new trends, as well as the recognized difficulties and implicit wishes of stakeholders (Unit 1). They are not restricted to feasible solutions at this early stage.

Method: Unit 2 employs methods that help the students to broaden their minds and encourage forethought. Inspired by foresight thinking [38], students learn to identify social and technological trends by considering 
examples from outside their core area and by tracking recent social and technological trends. Teachers can facilitate this by organizing excursions to research and development departments and laboratories, e.g., in 2018 we visited the showroom "Future Self-Service" and the „Future-Work Laboratory” of the Fraunhofer IAO in Stuttgart, Germany. Inspired by the trends, students brainstorm futuristic ideas which address a specific subaspect of their challenge. They need to capture their ideas as written or drawn mini-scenarios [39] so that the ideas become concrete.

Content: Apart from teaching methods and live experiences, teachers provide students with the newest research trends. In 2018, it considered the application of mixed-reality systems in counselling and service provision [40], the possibilities and challenges of IT-supported counselling [41, 42], and other trends of humancomputer interaction and man-machine interface [43].

Unit 2 gives the students the chance to think big and invent radical solutions. Accordingly, students acquire relevant knowledge of technological and social trends outside public agencies. They are thus confronted with approaches allowing them to use those trends in a creative manner reducing the barriers and pain points identified in Unit 1. This prepares them for dealing with rapid improvements and changes typical for digital transformation. Simultaneously, the municipalities involved learn about recent trends and developments with the potential to solve their specific problems.

\section{Unit 3: (e-)Service Design}

Based on the knowledge collected, practical experience and their initial, singular ideas (Unit 1 and 2), students have to design a holistic solution to the given challenge. In 2018, students had to develop the whole journey of a citizen claiming a building permit: from a selfservice point to a short encounter with a frontline officer up to the fully-fledged counselling from a building specialist. Methods such as customer journey mapping and various prototyping approaches (empathy prototyping, prototype storming, storytelling) are explained and students employ them while exploring the practical aspects of their vision.

Methods: During Unit 3 students participate in workshops involving citizens, public employees and other stakeholders such as architects, planners and engineers. The workshops are led by external facilitators, so that the students feel free to express their opinions and go beyond standard class interaction protocol. The stakeholders and students invited form mixed groups of up to seven people, who collaboratively engage in workshop activities. This gives the stakeholders direct impact on the prototypes and forces the students to deal with contradictory input. The workshops should lead to a consistent and feasible vision of a service.
After the workshop students are encouraged to identify the best or most promising solutions, to combine them and design an (e-)service including a new business process starting and ending with the touchpoints between the client (citizen) and the authority. Finally, students interview other stakeholders (not the one involved in the workshop) to find out, if the developed solution has an acceptable potential to solve the challenge. In particular, they confront the stakeholders with the prototypes and collect feedback. The results from the draft of a service design, starting with the first point of contact and ending with the final decision from the authority. The drafting task forces the students to reflect upon their ideas and gives them the opportunity to systematically review the complete input collected in this Unit. As a consequence, the ideas developed in the workshop undergoes at least two more iterations and revisions.

Content: In this unit, students learn to combine highly creative and technologically visionary solutions with demands and limitations of potential users and stakeholders. On one side they learn about formal and informal limitations at first hand from the stakeholders involved. On the other side, they are taught ways to negotiate and moderate between contradictory perspectives. Thereby, they learn how to bring together parties with opposing views and requirements while working together on a possible solution. Even if moderation and negotiation skills are not at the core of public administration curriculum, the increasing popularity of publicprivate partnerships require public administration employees to possess facilitation skills.

Unit 3 gives the students the chance to experience problem-solving-driven collaboration with different stakeholders and teaches them how to accommodate incompatible views and constraints by adequate project management and perseverance. Simultaneously, the municipalities involved do not only obtain concrete, evaluated ideas, but also receive methodological input and new impulses through the participation of their employees in the workshops.

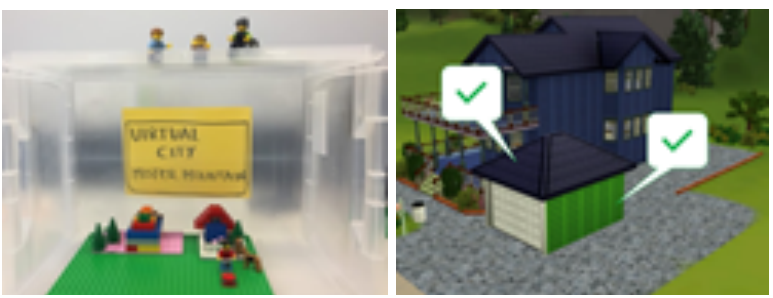

Figure 2. Two prototypes developed by students. Left: augmented reality environment for counselling. Right: 3D and Al-based assessment for self-service.

\section{Unit 4: Organizational changes}

New (e-)services normally require a re-organization of front- and back-office work including all aspects of process optimization, technology and public employees 
competences. To reach that, the Unit 4 addresses ancillary topics such as (a) business process redefinition, (b) job specification, and (c) room concepts. In 2018, the students proposed improvements concerning (a) data gathering and analysis, documentation and rearrangement of working steps, (b) description of tasks and competencies, measures for human resource development, and (c) analysis of changes and rearrangement of working space, and description of physical barriers.

Methods: In Unit 4, the students review the material collected and developed in previous Units and conduct and necessary additional interviews with communal managers and higher-level employees.

Content: The goal is to create an integrated approach allowing customers and employees to efficiently fulfill their tasks / requests, as well as improve quality of the service and the business process. Working in this, students learn to bring different threads together. The goal is to broaden their minds and to encourage holistic thought on working on an integrated approach.

\section{Results and Feedback}

\subsection{Method}

The module was run from 2015 to 2018 with approx. 50 students per year. Each year, there were one or two municipalities participating in the course. The students developed eight to ten different (e-)services annually specifically for municipalities. This section summarizes the feedback from the partners and students involved. While there was no systematic data collection (e.g., no course assessment questionnaires), the teachers employed the following ways to collect feedback:

After each unit the students had to summarize verbally what was new for them and what they thought would help them specifically to reach the given goal. Additionally, they had to make notes in their "learning diary". They were also asked about their opinion of the unit. So, they could give feedback by telling what they liked / disliked and what they would change.

At the end of the course we collected feedback: 1 . The public employees were asked to give feedback on the solutions addressing the questions: (a) which aspects do we want to implement and why in a short / middle / long term, and (b) what's impossible to implement and why. 2 . The students provided feedback answering two questions, "What have I learned considering (a) working on a real project and project management, (b) teamwork (c) working in a change project and (d) in general?" and "What is the most precious finding for me?" We can therefore refer to comprehensive feedback.

\subsection{Intermediate feedback and interventions}

At the beginning, all students were highly motivated. They appreciated working under real conditions in a real project and hoped that their results would be implemented. At the same time, they expressed their concern about failing and not coming up to the expectations of the public employees. So, they set their sights on the wishes and beliefs of public servants and could not understand why they had to focus on both. To avoid a onesided solution we created the slogan "citizen-centered and employee-oriented service" and introduced the sentence "The fear to be wrong is already the error" and started to repeat them like a mantra during the course.

Working on the given case it became obvious that the students were biased by the status quo of public administration and felt bound by the wishes of the public servants. For instance, in the 2015 case "digitalization of the customer relation's management" of the town's library, the employees wanted to keep their paper-based customer files even if the customers could sign the contracts digitally. The students took the librarian's wish as an order and stopped working on a comprehensive solution. Noticing this, we discussed their self-limitation. Their loyalty and obligation to fulfill the wishes of their future colleagues and managers became obvious. They forgot their goal to create a "librarian customer management system for the year 2030". So we decided to implement the rule "Meet the expectations of all stakeholders and exceed them through a forward-looking approach." Also, we decided to offer all students the possibility to collect experience from the perspective of the citizen/client. Therefore, from 2016 on, we added mystery shopping as well as self-service experience to Unit 1 instead of interviewing citizens about their experiences. The change of perspective worked out. In 2017 and 2018 the students worked without further intervention and produced balanced solutions.

Practical experience and empathy revealed yet another challenge. Students often focus on the internal processes of the authority and ignore the touch points of the customers. To avoid this, we implemented the next principle: "The business process starts and ends with the customers 'point of contact." Thanks to this intervention, they started to include contact with citizens in their analyses and prototypes.

Based on their experiences in public administration during their practical terms, the students who join the course in their seventh semester are already ingrained with the knowledge that there is little to no budget for internal changes. They tend to judge every idea automatically according to the availablility of a budget. Expensive ideas were thrown out, even if the future could offer potential resources. So we implemented the principle "First step: Think big - everything is possible! Second step: Find a way to achieve the vision starting with quick wins and ending with the maximum!" to make clear to the students that implemented ideas can generate value that is higher than the necessary investment. 
And, finally, students prefer working on safe ground and therefore choose already existing solutions in public administration. The experience from fieldwork seemed to limit their imagination. To provide external inspiration, from 2016 onward, we added excursions to research centers or innovative companies and included presentations by inventors and developers. This only worked out to a certain degree. When encouraged to look at different branches for inspiration, they refused: "These solutions are impossible for public administration!" Since our public-administration partners stressed the need for change, we established another rule: "Think out of the box!" This helped the students to include new developments and techniques, as well as new approaches. Since 2017, the students have been more or less automatically searching for new possibilities and inspiring solutions.

\subsection{Final feedback}

The students' ideas amazed public employees and managers. As one manager put it: "I didn't expect such well thought-through solutions!" Also, the municipal representatives value the interdisciplinary focus of the students, who consider ancillary topics such as law or municipality finances. Public employees highlight the creativity and students' drive to work on the "best" solution. They also notice limitations. They couldn't understand why the students could question existing laws and could make suggestions about changing / improving them, "because as a municipal employee you don't question existing law". On the whole, the project partners benefitted from the course, because it challenged them to "think big" and to "think out of the box" as well.

Apart from the comments, there is evidence for the real-world impact of the course (in the form of implemented concepts). In years 2015 and 2016, the managers from the participating municipalities used the course to introduce new ideas on how to digitalize business processes or change the service delivery. They gave their employees the chance to choose from the solutions proposed by the students in the sense of "cherry picking". As a result, ideas which suited them were implemented, such as an internal online-kindergarten event-calendar for parents ${ }^{1}$. In 2017, we received much interest from different departments of a single city. E-services and digital processes for ten different departments were designed. By now, the following four propositions have been fully/partially implemented: a green management, managing deficiencies ${ }^{2}$, a booking service for tourist city excursions ${ }^{3}$, and a service for lecturers and employees of a vocational training center to jointly develop the training program of the adult education center ("Volkshochschulprogramm"). This last solution was submitted

\footnotetext{
${ }^{1}$ https://www.sindelfingen.de/start/Bildung+Leben/kitas

${ }^{2} \mathrm{https}$ ://www.herrenberg.de/tools/mvs/
}

by the department to the "Lighthouse Award". Two other departments are in the process of implementation. Finally, in 2018 two groups of students, each with 24 members, competed against each other to design "a building service centre for local authorities", to improve the citizen's experience of obtaining a building permit. The involved municipality intends to proceed towards the implementation of idea. The authority decided at once to implement the "waiting room lights" idea that emerged during Unit 2 - it supports transparency of the number of customers waiting to be attended. A partner declared: "I didn't expect them [the students] to be able to think customer-oriented up to this degree and to work in depth!" Overall, the municipalities were engaged throughout the course, giving the students access to their employees and experts, supporting them during fieldwork, and finally being open to use ideas despite organizational limits. Each year the municipalities tried to recruit some of the graduates because of their competences mirrored by the newly designed services.

The final feedback from students varies. Asked about the most important aspect they learned, they pointed to the principles and rules i.e. "Think big" and "Think out of the box" and gave the feedback that having worked on a real case they now knew how to cope with resistance and hurdles. About $50 \%$ complained about the heavy work-load, some about the challenge of self-organization. Everyone felt prepared to meet future requirements resulting out of digital transformation. Some stated they no longer are afraid of the real world because they feel able to manage complex task. Others noticed that the possibility of changing public administration even though they had not thought so before. One stated: "For the first time I believe that changes in public administration are possible and I hope that I will work in a modernized administration." Overall, students have noticed the large difference between this course and other courses they attended so far. They highlighted its practical relevance but also acknowledged the amount of work that goes into digital transformation.

It is difficult to systematically collect feedback from the graduates but there is anecdotal evidence in favor of the course. One student wrote: "Now, in retrospect I can recognize the value of this project even better." Another student, currently working in the public sector, asked about being informed about future project results: "If there is a way to get the results of the following years, let me know." At least for those two students, the course had the envisioned impact.

\section{Discussion}

By introducing this course, we show that public administration departments have potential to impact the

\footnotetext{
${ }^{3}$ www.herrenberg.de/de/Stadtleben/Erlebnis-Herrenberg/Staunen-Erleben/Stadtfuehrungen/Historischer-Rundgang
} 
digital transformation in the public sector, if they combine practice-oriented project work with the adequate content. Through participation in the course, the municipalities learned, that digital transformation involves deep and radically innovative problem solving rather than the reinforcement of the status-quo with digital means $[7,8]$. Some even implemented the newly designed digital processes. So, thanks to the course, the municipalities obtain a new perspective on their status quo and are provided with well-thought through solutions. The students learn to apply a holistic approach to real-world practices while addressing new technology, business processes, organizational structure as well as the views of the stakeholders. The course facilitates an exchange between the public authorities and citizens through students and their ideas.

The solutions developed have proven that the students could effectively use the competences and skills necessary for digital transformation [9] and through their feedback they show that they value it. We claim that the proposed course supports the acquisition of these key competences by linking learning and teaching with a real project. However, this claim requires a systematic evaluation, e.g., by means of a formal measurement of those competencies. Since the course did not involve an exam, an assessment can be derived through feedback, developed ideas and artefacts. Anyway, the course provides a vehicle for transferring those skills, as opposed to the classic "chalk and talk" teaching style.

By offering this course, we jumped on the bandwagon. In recent years many universities (especially business and engineering departments) started offering courses where students are confronted with practical challenges provided by industry and work, with dedicated mentors from the industry partners to solve those problems $[13,14,16,17]$. The course described for public administration students follows this up by adopting concepts relevant to design thinking (agile prototyping, extensive field work, stakeholders' participation, and holistic approach). Furthermore, we prefer the idea of real-world challenges, proposed or developed together with practice partners rather than abstract challenges. This assures the high relevance of the work done by students and provides more value for the partners.

In addition, this paper responds to an ongoing discussion on public administration education. So far, it has been characterized by frequent calls for positioning digital transformation in public administration curricula $[12,13,14,18]$ and a limited guidance $[15,16,17]$. It pushes the discourse towards practical consideration and outlines the design of a particular course (Section 5) as well as the principles that emerged during the course (Section 6), which have been evaluated over four years of teaching. Furthermore, it provides evaluation data, including anecdotal evidence for the effectiveness of the course. While the evidence needs to be extended and systematized, the preliminary research confirms the necessity of teaching digital transformation and the great potential of courses with strong practical element.

Having worked for four years on the course, we noticed that teaching digital transformation allows students to deepen their insight and provides them with far more competences and skills than teaching about digital transformation. The course's practical focus and the direct link to the real-world make the students experience' the up- and downsides of digital transformation, including organizational limitations and the amount of work involved in a successful project. Also, the interaction with managers from the participating agencies prepares the students for establishing a perspective of the leader, in addition to those of an employee and a customer.

\section{Conclusion and Limitations}

Digital transformation will increasingly affect the work practice and workflows in the public sector. However, public administration education still lacks widespread standards and guidance on how to prepare public administration students for digitalization. This case study offers an overview of a course, which - according to the evidence collected - can be well integrated into a public administration curriculum and produces an outcomes valuable for students and partners. This case study and, in particular, the systematic overview of the course, should help teachers at public administration schools and departments copy the concept. The decision makers and managers in the public sector can find inspiration for entering into research and teaching partnerships with local public administration schools. Finally, the researchers who study the potential and obstacles of digital transformation can recognize the role of education better and get access to practical examples of the successful application of methods characteristic for digital transformation in business for the public sector. Overall, the paper adds to the discussion concerning the modernization of the public sector and updating of public administration curricula.

But applicability comes with limitations. The module is especially designed for the Universities of Public Administration of Baden-Württemberg being limited by their legal framework and the current course programme influenced by Baden-Wuerttembergs' Ministry of Internal Affairs, the "Gemeindetag" and "Städtetag". Therefore, other universities might have a different framework (in particular, the overall structure of the study program), so that adaptations might be necessary. Also, more systematic and extended evaluation could further contribute to the empirical aspect of the study. Still, the paper sets important impulses for practice and research. 


\section{Acknowledgments}

Herewith we want to express our best gratitude to the involved communes and cities, who supported the course over the last years by contributing relevant problems, offering access to the relevant stakeholders and otherwise supporting the teachers and the students of the course. In particular, our thanks go to the City of Sindelfingen, Mrs. Margit Gaeng, the City of Herrenberg, Franziska Biehler, Stefan Kraus, Tom Michael, as well as EnBW, Karin Bandt. We, also, thank Gerhard Schwabe for his valuable inputs to the paper, as well as the anonymous reviewers who provided precise and interesting feedback. Finally, we thank the students who participated in the course and wish them all the best for their career in the digitalized public administration.

\section{References}

[1] McAfee A, Brynjolfsson E. Machine, platform, crowd: harnessing our digital future. Norton \& Company, NY, 2017.

[2] Kraemer K.L., King J.L. Computers and administrative reform: Will the time after e-Government be different? 2003.

[3] Lenk K. Reconstruction Public Administration theory from belwo. IP, 12(4), 2007, pp. 207-212.

[4] Hammerschmid G. Vom Wunsch zur Wirklichkeit: Drei Schritte zur Digitalen Verwaltung. Trend, 2017.

[5] Probst G., Raub S., Romhardt K. Wissen managen. Gabler Wiesbaden, $5^{\text {th }}$ edition, 2006.

[6] Lankshear C.; Knobel M. (eds.). Digital literacies: concepts, policies and practices. Peter Lang, New York, 2008.

[7] World Economic Forum 2017: The Digital Transformation Initiative: Mining and Metals Industry. WEF, Geneva, 2017.

[8] Digitale Initiative: Shaping digital transformation in science. Digital Information Initiative. Göttingen 2016, pp. 1-15.

[9] Janowski T. Digital government evolution: From transformation to contextualization. GIQ, 32(3), 2015, pp. 221-236.

[10] Kraemer L., King J.L: IT and Administrative Reform: Will e-Government Be Different? IJEGR, 2006.

[11] Hunnius S., Schuppan T. Competency Requirements for Transformational E-Government. Proc. HICSS, 2013.

[12] Kirchner J. et al. Future Skills: Which skills are lacking in Germany. Stifterverband für die Dt. Wissenschaft 2017.

[13] Lande M., Leifer L. Prototyping to Learn: Characterizing Engineering Students' Prototyping Activities and Prototypes. DS 58-1: Proc. ICED, 2009.

[14] Leifer L.J, Steinert M. Dancing with Ambiguity: Causality Behavior, Design Thinking, and Triple-Loop-Learning. In: Management of the Fuzzy Front End of Innovation. Springer Intl. Publ. 2014, pp. 141-158

[15] Uebernickel F., Brenner W., Naef T., Pukall B., Schindlholzer B. Design Thinking: Das Handbuch. Frankfurter Allgemeine Buch, Frankfurt am Main, 2015.
[16] Carleton T., Leifer L., Stanford's ME310 Course as an Evolution of Engineering Design. In: Proc. CIRP Design Conference, 2009, pp. 547-555.

[17] Dym C.L., Agogino A.M., Eris O., Frey D.D., Leifer L.J. Engineering Design Thinking, Teaching, and Learning. JEE, 94, 2005, pp. 103-120.

[18] Fichman R. G., Dos Santos B. L., Zheng, Z. E. "Digital Innovation as a Fundamental and Powerful Concept in the Information Systems Curriculum.” MISQ, 38(2), 2014.

[19] Kim S., Layne K. "Making the Connection: E-Government and Public Administration Education," JPAE, 7(4), 2001, pp. 229-240.

[20] Jones L. R., Thompson F., Zumeta W. Public Management for the New Millennium: Developing Relevant and Integrated Professional Curricula. IPMR, 2(2), 2001 pp. 19-38

[21] Schelin S. H. Training for Digital Government. In: Pavlichev A., Garson G. (Eds.) Digital Government: Principles and Best Practices, Hershey, PA, 2004, pp. 263-275.

[22] Wu X., He J. "Paradigm Shift in Public Administration: Implications for Teaching in Professional Training Programs". PAR, 69(1), 2009, pp. S21-S28.

[23] Babaoglu C., Akilli H.S., Demircioglu M. A. "E-Government Education at the Public Administration Departments in Turkey," in Proc. Intl. Conf. Theory and Practice of Electronic Governance: ACM, 2012, pp. 71-74.

[24] Biasiotti M. A., Nannucci R. "Teaching E-Government in Italy." In Electronic Government, Lecture Notes in Computer Science, Springer, 2004 pp. 460-463.

[25] Estevez E., Janowski T. "Landscaping Government Chief Information Officer Education.” In: Proc. HICSS, 2013, IEEE.

[26] Janowski T., Estevez E., Ojo A. "Conceptualizing Electronic Governance Education.” In: Proc. HICSS, 2013. IEEE.

[27] HVF: Modulhandbuch Public Administration B.A. 2013.https://www.hs-ludwigsburg.de/fileadmin/Seitendateien/studium/public_management/Modulhandbuch_Modulreform_01.03.2017-.pdf, accessed 31-1-2019.

[28] Ozga, J. "From Research to Polica and Practice: Some Issues in Knowledge Transfer" 2004. http://www.ces.ed.ac.uk /PDF\%20Files/Brief031.pdf, accessed 2-20-2019

[29] Kapucu N. Competency-based Curriculum Mapping as a Tool for Continuous Improvement for Master of Public Administration Programs. IJOPA, 40, 2017, pp. 968-978.

[30] Perrenet J.C., Bouhuijs P.A.J.; Smits J.G.M.M. "The suitability of problem-based learning for engineering education: theory and practice." Teach. in Higher Edu., 5(3), 2000.

[31] Heitmann G. Project-oriented study and project-organized curricula: A brief review of intentions and solutions. EJEE, Taylor\&Francis, NL, 21(2), 1996, pp. 121-131.

[32] Milam D.M. Practitioner in the Classroom: Bringing Local Government Experience into the Public Administration Curriculum. Public Adm. Rev., 63(3) 2003, pp. 364-369.

[33] Reis, J. et al. "Digital Transformation: A Literature Review and Guidelines for Future Research. In: Proc. WorldCIST, 2018, pp. 411-421. 
[34] Gill M., Van Boskirk, Sh. The Digital Maturity Model 4.0.2016 https://forrester.nitro-digital.com/pdf/Forresters\%20Digital\%20Maturity\%20Model\%204.0.pdf, 12-20-2016

[35] Berghaus S., Back A. States in Digital Business Transformation: Results of an empirical Maturity Study. In: Proc. MCIS, 2019.

[36] Nail R. How to teach companies digital future readiness In: Diehn T.: Die Zukunftsmacher und ihre Visionen für Bildung und Ausbildung, Forschung und Technik, 2018.

[37] Dolata M., Schwabe G. "Design Thinking in IS Research Projects," In: Brenner W., Uebernickel F. (eds.) Design Thinking for Innovation, Springer, Berlin Heidelberg, 2016.

[38] Carleton T, Cockayne W, Tahvanainen A. Playbook for strategic foresight and innovation. Takes Publ., 2013.
[39] Rosson M. B., Carroll J. M. "Usability Engineering: Scenario-Based Development of Human-Computer Interaction".Morgan Kaufmann,San Francisco CA, 2002.

[40] Dolata M. et al. "Welcome, Computer! How Participants Introduce a Collaborative Application during Face-to-Face Interaction?”In: Proc. INTERACT 2019.

[41] Dolata M., Schwabe G. "Tuning in to More Interactivity - Learning from IT Support for Advisory Service Encounters." I-Com, 16(1), 2017 pp. 23-33. De-Gruyter.

[42] Dolata M., Schwabe G. "Don't Be Afraid! Persuasive Practices in the Wild." CSCW 2018, Springer, Amsterdam, 27(3-6), 2018 pp. 427-462.

[43] Richter A. et al. "Digital Work Design." In: Digital Work Design. 60(3), 7/2018, pp. 1-6 